\title{
Differential bioaccumulation and translocation patterns in three mangrove plants experimentally exposed to iron. Consequences for environmental sensing ${ }^{\text {मे }}$
}

\author{
Hiulana Pereira Arrivabene ${ }^{a}$, Caroline Quenupe Campos ${ }^{b}$, Iara da Costa Souza ${ }^{\text {, }}$ \\ Daniel Alberto Wunderlin ${ }^{\mathrm{d},{ }^{* *}}$, Camilla Rozindo Dias Milanez ${ }^{\mathrm{b}}$, \\ Silvia Rodrigues Machado ${ }^{\text {a, * }}$
}

a Universidade Estadual Paulista “Júlio de Mesquita Filho" - UNESP, Instituto de Biociências de Botucatu, Departamento de Botânica, 18618-970, P.O. Box 510, Botucatu, São Paulo, Brazil

${ }^{\mathrm{b}}$ Universidade Federal do Espírito Santo, Centro de Ciências Humanas e Naturais, Departamento de Ciências Biológicas, 29075-910, Vitória, Espírito Santo, Brazil

` Universidade Federal de São Carlos, Centro de Ciências Biológicas e da Saúde, Departamento de Ciências Fisiológicas, 13565-905, São Carlos, São Paulo, Brazil

d ICYTAC, Instituto de Ciencia y Tecnología de Alimentos Córdoba, CONICET and Dpto. Qca. Orgánica, Fac. Cs. Químicas, Universidad Nacional de Córdoba, Ciudad Universitaria, 5000, Córdoba, Argentina

\section{A R T I C L E I N F O}

\section{Article history:}

Received 15 December 2015

Received in revised form

13 April 2016

Accepted 3 May 2016

Available online 21 May 2016

\section{Keywords:}

Histochemistry

Iron bioaccumulation

Iron plaque

Iron translocation

Mangrove pollution

Pollution sensing

\begin{abstract}
A B S T R A C T
Avicennia schaueriana, Laguncularia racemosa and Rhizophora mangle were experimentally exposed to increasing levels of iron $\left(0,10,20\right.$ and $100 \mathrm{mg} \mathrm{L}^{-1}$ added Fe(II) in Hoagland's nutritive medium). The uptake and translocation of iron from roots to stems and leaves, Fe-secretion through salt glands (Avicennia schaueriana and Laguncularia racemosa) as well as anatomical and histochemical changes in plant tissues were evaluated. The main goal of this work was to assess the diverse capacity of these plants to detect mangroves at risk in an area affected by iron pollution (Vitoria, Espírito Santo, Brazil). Results show that plants have differential patterns with respect to bioaccumulation, translocation and secretion of iron through salt glands. L. racemosa showed the best environmental sensing capacity since the bioaccumulation of iron in both Fe-plaque and roots was higher and increased as the amount of added-iron rose. Fewer changes in translocation factors throughout increasing added-iron were observed in this species. Furthermore, the amount of iron secreted through salt glands of $L$. racemosa was strongly inhibited when exposed to added-iron. Among three studied species, A. schaueriana showed the highest levels of iron in stems and leaves. On the other hand, Rhizophora mangle presented low values of iron in these compartments. Even so, there was a significant drop in the translocation factor between aerial parts with respect to roots, since the bioaccumulation in plaque and roots of $R$. mangle increased as iron concentration rose. Moreover, rhizophores of $R$. mangle did not show changes in bioaccumulation throughout the studied concentrations. So far, we propose $L$. racemosa as the best species for monitoring iron pollution in affected mangroves areas. To our knowledge, this is the first detailed report on the response of these plants to increasing iron concentration under controlled conditions, complementing existing data on the behavior of the same plants under field exposure.
\end{abstract}

(C) 2016 Elsevier Ltd. All rights reserved.

\footnotetext{
ش This paper has been recommended for acceptance by W. Wen-Xiong.

* Corresponding author.

** Corresponding author.

E-mail addresses: dwunder@fcq.unc.edu.ar (D.A. Wunderlin), smachado@ibb. unesp.br (S.R. Machado).
}

\section{Introduction}

Mangroves are part of the ecosystem continuum from terrestrial to fully marine environments that occur at the boundary between land and sea, and are flooded regularly by the tide (Clough, 2013). Coastal wetlands have been recognized for their ability to stabilize shorelines and to protect coastal communities. Coastal wetland 
vegetation is an effective shoreline buffer, which acts as a natural barrier to stabilize fine sediment, preventing coastal erosion. Moreover, they reduce effects of storms and flooding, maintain water quality and biodiversity, and support a wide range of wildlife. Mangroves may have an indirect value in the protection of coastal property and economic activities such as fishery (Barbier et al., 2011; Vo et al., 2012). However, despite all the goods and services provided around the world, estimated at $\$ 1.7$ to $\$ 2.8$ billion per year (Brander et al., 2012; Costanza et al., 1997), mangroves have the fastest rates of loss of ecosystems worldwide, and are increasingly impacted by pollution (Valiela et al., 2001). Among the contaminants, pollution by metals is a concern, since these elements can be uptaken, transferred and involved in metal biomagnification along the food chain, generating toxicity for the biota (Cardwell et al., 2013; Nica et al., 2012).

Metal accumulation in mangrove sediment is favored by its high capacity of absorption of organic matter and small particles (Zhou et al., 2010). The anaerobic environment, in addition to high levels of organic matter and iron sulfide, in mangrove sediments enhance iron settling, and the accumulation of metals. Therefore, iron is responsible for modulating the bioavailability and redox characteristics of metals in sediments (Morse and Rickard, 2004).

Vascular plants mangroves are crucial to the dynamics of the estuarine ecosystem, strongly influencing the processes of metals retention, with unique biological mechanisms. Some mechanisms involved in the resistance of mangrove plants to metals, namely the accumulation of metals in roots in comparison with the aerial parts of the plants, have been reported (Nath et al., 2014). These mechanisms involve the formation of an iron (Fe) plaque on the root surface (Cheng et al., 2014; Du et al., 2013), and metal retention in the root (epidermis and endodermis) (Lu et al., 2014; MacFarlane and Burchett, 2000). Evidence suggests that the extent of Feplaque formed on mangrove root is species-specific (Pi et al., 2011) and that the amount of Fe-plaque can be related to adaptive changes in the root anatomy in response to pollution (Pi et al., 2010). An additional adaptive response in some mangrove plants is the secretion of metals through salt glands (MacFarlane and Burchett, 1999; 2000; Naidoo et al., 2014).

Avicennia schaueriana Stapf \& Leechm. ex Moldenke, Laguncularia racemosa (L.) C.F. Gaertn. and Rhizophora mangle L. are mangrove species, commonly found in Brazil (Giri et al., 2011; Tomlinson, 1994). These plants are well adapted to saline wetlands, presenting aerenchymatose roots with air gaps that are usually bigger in Avicennia schaueriana and Laguncularia racemosa in comparison with Rhizophora mangle, which additionally shows warming root cells (Menezes, 2006; Youssef and Saenger, 1996). These three species show different ways to cope with the saline sediment. A. schaueriana and $L$. racemosa are species with salt glands in leaves; conversely, R. mangle have glabrous leaves (Tomlinson, 1994). Mangrove plants secreting salt through salt glands are capable of absorbing more salt through the root (saltincluding species), which has been proposed as a mechanism that facilitates the absorption of metals, resulting in a higher bioaccumulation in these plants (Bernini et al., 2006; Cuzzuol and Campos, 2001; Sarangi et al., 2002).

The presence of iron mines close to mangrove areas can result in an additional load of metals in the sediment; particularly iron (Veerasingam et al., 2015). The state of Espírito Santo (Brazil) has the largest iron production of the country, being the biggest mining harbor in Brazil (IBEF, 2011). Levels of iron in sediments of this area reach $23 \mathrm{mg} \mathrm{g}^{-1}$ (Arrivabene et al., 2015), which are above levels found in other polluted mangrove areas (Defew et al., 2005; Lacerda et al., 1989; Sadiq and Zaidi, 1994; Sarangi et al., 2002; Sherman et al., 1998; Silva et al., 1990).

Some field studies have been carried out to evaluate the bioaccumulation of iron in mangrove plants (Souza et al., 2014a, 2014b, 2015). However, to our knowledge, there are few studies on the bioaccumulation of iron under controlled conditions (Cheng et al., 2012), looking to isolate the behavior of this metal from the complex matrix present in mangrove sediments, like the presence of different amounts of organic matter, dissolved oxygen, granulometry, etc. (Arrivabene et al., 2015). Furthermore, previous studies did not report the iron distribution in all plant compartments. It is worth to mention that, in addition to being a micronutrient, iron can reach concentrations toxic to the plant if its amount in sediments as well as its bioavailability are high enough (Kobayashi and Nishizawa, 2012).

Considering the above-described evidence, the main goal of this work was to evaluate the diverse capacity of these three plants to absorb, translocate and bioaccumulate iron in different plant compartments, as well as to evaluate changes in the plant anatomy. Thus, we look to verify if these plants can be used as pollution sentinels in an area with mangroves at risk because of iron pollution (Vitoria, Espírito Santo, Brazil).

\section{Materials and methods}

\subsection{Experimental set up}

Propagules of $A$. schaueriana, L. racemosa and $R$. mangle were collected at the ecological reserve of the Lameirão county (Estação Ecológica Municipal Ilha do Lameirão), State of Espírito Santo, Brazil, during the spring 2013 (A. schaueriana), or the summer 2014 (L. racemosa and $R$. mangle). Propagules were transported to a greenhouse at the Federal University of Espírito Santo, where they were cultivated in pre-cleaned PVC pots $(2.8 \mathrm{~L}$ each) containing washed sand. Sand pots were stored in receptacles containing a nutritive medium (Hoagland and Arnon, 1950), with 0.25 ionic strength and a salt content of $7 \mathrm{~g} \mathrm{~L}^{-1}$. The level of the nutritive medium was ca. $3 \mathrm{~cm}$ during plant grow, and $\mathrm{ca} .7 \mathrm{~cm}$ during exposures, simulating mangrove conditions without the presence of organic matter. The nutritive medium was covered with a black PVC film to prevent photo-oxidation.

Propagules were developed during eight months, afterward plants were used for exposure. Exposures were performed by adding 0 (control), 10, 20 and $100 \mathrm{mg} \mathrm{L}^{-1} \mathrm{Fe}(\mathrm{II}) \mathrm{SO}_{4}$ (to simulate the bioavailable form of iron), disodium EDTA and MES buffer ( $1 \mathrm{mM}$, $\mathrm{pH} 6$ ) to the nutritive medium (which already contained $0.53 \mathrm{mg} \mathrm{L}^{-1} \mathrm{Fe}$ as $\mathrm{FeCl}_{3}$ ). Iron concentrations of 10 and $20 \mathrm{mg} \mathrm{L}^{-1}$ were selected as they are close to values found in the interstitial water during field studies in the mangrove area of Espírito Santo (Arrivabene et al., 2015). The highest concentration (100 $\mathrm{mg} \mathrm{L}^{-1}$ ) was selected to simulate a more toxic condition, with iron levels exceeding current environmental levels, similar to the levels found during an incident like the recent mine dam break in the neighbor State of Minas Gerais (Brazil). The nutritive medium was renewed weekly.

Sets of five independent plants $(n=5)$ from each species (randomly selected) were exposed to different iron concentrations during eight weeks. After exposure, plants were harvested and analyzed as described below.

\subsection{Chemical analysis of iron}

Glassware and plasticware used for sampling preparation and analysis were previously washed using a neutral detergent Extran MA $02(5 \% \mathrm{v} / \mathrm{v}), 15-50 \% \mathrm{v} / \mathrm{v}$ nitric acid (63.7\%) sub-boiling grade and ultrapure water ( $\left.<5 \mu \mathrm{g} \mathrm{L}^{-1} \mathrm{TOC}\right)$. Ultra-pure water was obtained from a purification system Arium 61316-RO, plus Arium 611 UV (Sartorius, Germany). Nitric acid sub-boiling grade was 
prepared from analytical grade acid, using a sub-boiling distiller (Figmay, Córdoba, Argentina). The purity of the nitric acid was checked by Mass Spectrometry Inductively Coupled Plasma (ICPMS) (Agilent 7500cx, USA).

Iron concentrations were determined in triplicate by ICP-MS, using an ASX-100 autosampler (CETAC Technologies, Omaha, NE), according to Usepa (2009) methods. Quality assurance (QA) and quality control (QC) were performed using a certified reference material (CRM): peach leaves NIST SRM 1547. Recoveries from CRMs were above $80 \%$ as recommended by USEPA. Spiked samples were also prepared for roots, stems, rhizophores and leaves to verify the matrix effect. Thus, standard Merck VI CertiPUR ${ }^{\circledR}$ (Merck Química, Buenos Aires, Argentina) was added to dried plant materials; the rest of the procedure was the same as used for nonspiked samples. The average recovery of these assays ranged from 92 to $105 \%$.

\subsubsection{Iron in plaque}

The extraction of the Fe-plaque was performed using the dithionite-citrate-bicarbonate technique (DCB), which is effective in extracting the iron retained in the Fe-plaque present along the root surface of plants. There are different reports on the proportion of reagents used in this method (Liu et al., 2004; Otte et al., 1991; Taylor and Crowder, 1983). Thus, we carried out a comparison between these three methods (Table 1S) to verify the best experimental set up to be used with our samples. From Table 1S, we can see that the method proposed by Taylor and Crowder (1983) allows the highest extraction of iron from the Fe-plaque, while no significant differences were found for total iron (Fe-plaque + internal root) among the three methods. Therefore, we used the protocol reported by Taylor and Crowder (1983) to extract the Fe-plaque. Briefly, the entire root system was washed with reverse osmosis water (RO-water) and air-dried. Next, an amount equivalent to $0.2 \mathrm{~g}$ dry root was stirred at room temperature for $3 \mathrm{~h}$ in a cold DCB solution (40 mL of $0.3 \mathrm{M} \mathrm{Na}_{3} \mathrm{C}_{6} \mathrm{H}_{5} \mathrm{O}_{7} \cdot 2 \mathrm{H}_{2} \mathrm{O} ; 5 \mathrm{~mL}$ of $1 \mathrm{M} \mathrm{NaHCO}_{3}$, and $3 \mathrm{~g}$ de $\mathrm{Na}_{2} \mathrm{~S}_{2} \mathrm{O}_{4}$ ) (Taylor and Crowder, 1983). The approximate ratio between fresh and dry mass of roots was analyzed previously in roots from different individuals. After DCB extraction, roots were rinsed with RO-water, dried in an oven $\left(37^{\circ} \mathrm{C}\right)$ until constant weight. The DCB extraction solution was filtered using nitrocellulose $0.45 \mu \mathrm{m}$ filters (Millipore, USA), acidified with ultra-pure $\mathrm{HNO}_{3}$, and stored at $4{ }^{\circ} \mathrm{C}$ until analysis.

\subsubsection{Iron in roots, stems, rhizophores and leaves}

Roots, stems, rhizophores and leaves samples were washed with RO-water, dried at $37{ }^{\circ} \mathrm{C}$ until constant weight, grinded and homogenized with a mortar. All samples were digested according to Chappaz et al. (2012) with slight modifications, using $4 \mathrm{~mL}$ nitric acid (70\% ultra-pure, sub-boiling grade) and $1 \mathrm{~mL} \mathrm{HCl} \mathrm{(37 \% ,} \mathrm{ultra-}$ pure sub-boiling grade), in pre-cleaned PTFE tubes (Sevillenex, USA) at constant temperature during $24 \mathrm{~h}$. All samples were filtered $\left(0.45 \mu \mathrm{m}\right.$, Millipore, USA) and stored at $4{ }^{\circ} \mathrm{C}$ until analysis. Controls were prepared using the same protocol without sample (only reagents).

Translocation factors (TF) were calculated between different plant compartments: TFsr: [Fe] stem/[Fe] root; TFls: [Fe] leaves/[Fe] stem; TFlr: [Fe] leaves/[Fe] root; and TFsh: [Fe] (leaf + stem)/[Fe] root. For $R$. mangle, particularly, TFsh was calculated as $[\mathrm{Fe}]$ $($ leaf + stem + rhizophore $) /[\mathrm{Fe}]$ root.

\subsubsection{Iron in the secretion from salt glands (A. schaueriana and $L$. racemosa)}

The entire procedure was performed within a PVC cubic structure, protecting leaves from possible atmospheric contamination by particulate iron, including dust. Leaves from the third node were successively washed with 5\% v/v Extran MA 02 neutral detergent and then with RO-water. The PVC cubic structure was wrapped using a transparent PCV film, containing small orifices to prevent saturation with water vapor, and minimize interference with the photosynthetically active radiation on the leaves, which could cause the stomata closure and consequent reduction in the flow of transpiration and secretion (as observed by Scholander et al., 1962). After three days, leaves were collected and immersed in DCB solution for $3 \mathrm{~h}$ (Taylor and Crowder, 1983). Leaves were also used to determine glandular density $\left(\mathrm{n}^{\circ} \mathrm{mm}^{-2}\right)$ by the printing technique, using a drop of cyanoacrylate ester adhesive (Super-Bonder ${ }^{\mathbb{R}}$ ) in a histological slide. Thus, the obtained foliar surface was analyzed by microscopy (Nikon E200 microscope, Tokyo, Japan). Six random optical fields were measured from each foliar surface, documented with the Tsview v.6.1.3.2 software (Tucsen Imaging Technology Co. Limited). In order to calculate secretion rate per area and mass unit, both leaf area $\left(\mathrm{cm}^{2}\right)$ and leaf dry weight $(\mathrm{g})$ were measured. The leaf area was measured with the Area Meter LI-COR 3100 (Lincoln, USA), while the dry mass was obtained by weighing the samples after they were oven-dried at $60{ }^{\circ} \mathrm{C}$ until constant weight.

\subsection{Root anatomy}

The thickness of epidermal, cortex and total root, air gap area and diameter of vascular cylinder of absorption roots were calculated. Roots were dehydrated using ethanol series, embedded in historesin (Leica, Germany), cross-sectioned (8-10 $\mu \mathrm{m}$ thick) using a rotary microtome, and stained with $0.05 \%$ toluidine blue, $\mathrm{pH} 4.7$ (O'Brien et al., 1964). Thirty measurements per root section were performed using the software Nikon NIS-Elements (Tokyo, Japan). Pictures from analyzed sections were recorded using a light microscope (Nikon Eclipse 50i, Tokyo, Japan), equipped with a digital camera.

To compare differences between species, we considered the variance of data obtained from each treatment, which were compared to the corresponding control.

\subsection{Iron histochemistry staining of roots, stems and leaves}

Freehand sections from roots (ca. $2 \mathrm{~cm}$ root apex), stems (ca. $10 \mathrm{~cm}$ from the shoot apex), and leaves (middle third) were obtained with a razor blade and immersed in Perl's reagent (1\% potassium ferrocyanide, $2 \% \mathrm{HCl}$ in a $1: 1$ proportion; Bancroft et al. 2008) for Fe(III) detection. Additionally, another set of plants sections were treated with Lillie's reagent $(400 \mathrm{mg}$ of potassium ferricyanide in $40 \mathrm{~mL} \mathrm{0.5 \%} \mathrm{HCl}$; Bancroft et al., 2008) for $\mathrm{Fe}(\mathrm{II})$ detection. After $24 \mathrm{~h}$, sections were washed; pictures from analyzed sections were recorded using a light microscope (Nikon Eclipse 50i, Tokyo, Japan), equipped with a digital camera. Positive staining was verified by the Prussian blue color of Perl's reagent (ferric iron), or by the Turnbull blue from Lillie's reagent (ferrous iron).

\subsection{Statistical analysis}

All data were tested for normal distribution. For chemical data (mainly non-normal distribution) Kruskal-Wallis test was applied, while for biological data (mainly normal distribution), one-way analysis of variance (ANOVA), followed by the Tukey's test were used; both with a significance level $P<0.05$. Data are reported as mean \pm standard deviation for biological data showing normal distribution, while median \pm first quartile is reported for chemical data with non-normal distribution.

The following multivariate statistical methods were applied to different sets of data (chemical, biological and combination parameters): canonical correlation analysis (CCA), Spearman's rank 
correlation coefficient and generalized Procrustes analysis (GPA). CCA and Spearman's rank were used to analyze correlations between two groups of variables (chemical and biological). Spearman's rank shows correlations between variables. CCA improves the information between iron bioaccumulation and biological responses. GPA was used with six dataset (chemical and biological data from three studied species) to understand their distribution and correlations.

Multivariate statistical methods are important to highlight the contribution of various variables in the model and their ability to discriminate one class from another (Wunderlin et al., 2001). The statistical package Infostat (Di Rienzo et al., 2010) were used for analyzes.

\section{Results}

\subsection{Iron concentration in plaque, roots, stems, leaves and saline secretion from salt glands}

Fig. 1 and Tables 2S and 3S (supplementary material) show the iron concentration in plaque, roots, stems and leaves of three studied species under different concentrations of added-iron. Fig. 2 and Tables $2 \mathrm{~S}$ and $3 \mathrm{~S}$ show the iron concentration in secretions from salt glands. Controls show presence of iron due to the content of this element in the nutritive medium. These results evidence that the Fe-plaque is a place of high iron accumulation in these plants (Table 2S). L. racemosa accumulated the highest amounts of iron in the plaque and roots, while $A$. schaueriana presented the highest levels in both stems and leaves (Fig. 1 and Table 2S). Also in Fig. 1, it is evident that the bioaccumulation of iron in the plaque and roots of $L$. racemosa increased progressively as the added-iron concentration rose. Fig. 2 and Table $2 \mathrm{~S}$ show that the iron secretion through salt glands is strongly inhibited in $L$. racemosa at iron concentrations above controls, while $A$. schaueriana did not show a noticeable drop from controls to the highest added-iron concentration used. On the other hand, salt glands density in both A. schaueriana and $L$. racemosa do not significantly vary throughout the different amounts of added-iron (Table 2S).

\subsection{Translocation factors}

Fig. 3 and Table 2S show translocation factors between different parts of the studied plants, exposed to diverse added-iron amounts. A drop in TF between aerial parts of $R$. mangle and its root (TFsr, TFlr and TFsh) becomes evident. Conversely, $R$. mangle showed a trend to increase TF between stems and leaves, although not statistically significant (Fig. 3, Table 2S). The rest of studied species did not show changes in TF at all dosages of iron, although A. schaueriana had a significant drop in $\mathrm{TF}$ when exposed to $100 \mathrm{mg} \mathrm{L}^{-1} \mathrm{Fe}(\mathrm{II})$. On the other hand, $L$. racemosa evidenced a drop in TF only between leaves and stems, and between leaves and roots, at the maximum iron concentration used (Fig. 3, Table 2S). In general, $L$. racemosa presented the lowest TF among the three studied mangrove plants (Table 2S).

\subsection{Root anatomy}

Table 4S shows studied anatomical parameters for roots of the three studied species. Most analyzed parameters did not show significant changes throughout studied added-iron concentrations. The parameters showing changes were thickness of cortex and root in A. schaueriana, with higher values in controls compared to exposed plants. Additionally, the root of $L$. racemosa was significantly thinner in plants exposed to $100 \mathrm{mg} \mathrm{L}^{-1}$ and thicker upon exposure to $20 \mathrm{mg} \mathrm{L}^{-1}$ (Fig. 4).

\subsection{Histochemistry}

Figs. 5-7 show results from histochemical analysis. In general, there was no difference in iron bioaccumulation sites under different dosages of Fe.

From Fig. 5 we can observe the main places of iron bioaccumulation in roots. Mainly the epidermis, but also cortex, were the areas showing the highest accumulation of both iron species ( $\mathrm{Fe}(\mathrm{II})$ and $\mathrm{Fe}(\mathrm{III})$ ) in the three studied species. Iron was also detected in vessel elements of $R$. mangle and in vascular cambium of L. racemosa exposed to the highest dose $\left(100 \mathrm{mg} \mathrm{L}^{-1}\right)$.

Fig. 6 shows that the vascular cambium of $L$. racemosa and the periderm of $R$. mangle were the main places for bioaccumulation of both iron species in stems from these two plant species. Conversely, in A. schaueriana it was not possible to verify the main places for iron bioaccumulation within the stem. However, stems of A. schaueriana showed presence of $\mathrm{Fe}(\mathrm{II})$ and $\mathrm{Fe}(\mathrm{III})$ in epidermis, subepidermis, lenticel, xylem (mainly in protoxylem) and salt glands cells. Moreover, Fe(II) was massively detected in vessel elements, phloem, cortical parenchyma and pith of $A$. schaueriana.

Fig. 7 shows some places of iron bioaccumulation in leaves. The main place for bioaccumulation in A. schaueriana was the water storage parenchyma and, additionally, the cortex of the midvein, epidermis, salt glands and spongy parenchyma. On the other hand, L. racemosa presented the main iron bioaccumulation in its xylem, but also lower bioaccumulation in salt glands, and in both water storage and palisade parenchyma. Finally, the bioaccumulation of iron in leaves of $R$. mangle occurred in several places, mainly in the cortex of the midvein, and in both palisade and water storage parenchyma.

\subsection{Statistical analysis}

Chemical data (Table 2S) and anatomical information (Table 4S) were independently evaluated for each plant species to assess the plant that best correlates the bioaccumulation with changes in the anatomy. CCA demonstrates that $L$. racemosa was the species showing the best correlation between chemical and biological matrix $\left(\mathrm{R}^{2}=0.98, P=0.01\right)$, followed by $A$. schaueriana $\left(\mathrm{R}^{2}=0.97\right.$, $P=0.03)$, with no significant correlation for $R$. mangle $\left(\mathrm{R}^{2}=0.89\right.$, $P=0.3)$.

Spearman test showed a positive correlation between the iron concentration in the Fe-plaque and the amount of iron in roots of $L$. racemosa (Spearman $\mathrm{R}=0.80$ ) and $R$. mangle (Spearman $\mathrm{R}=0.82$ ). In addition, a negative correlation was found between iron concentration in plaque and translocation factors to $R$. mangle (Spearman $\mathrm{R}$ for TFsr $=-0.77$, TFlr $=-0.84$, TFsh $=-0.84$ ) and L. racemosa (Spearman $\mathrm{R}$ for $\mathrm{TFl} r=-0.64$ ). There was no correlation between Fe concentration in Fe-plaque and root biomass for any of the three species (Spearman $\mathrm{R}$ for $L$. racemosa $=-0.08$, A. schaueriana $=-0.07, R$. mangle $=-0.25$ ). No significant correlation $(P>0.05)$ was found between the density of salt glands and the concentration of iron in the secretion from $A$. schaueriana and L. racemosa. Furthermore, no significant correlation was found between the iron concentration from salt glands secretion and the amount of iron in leaves of $A$. schaueriana and L. racemosa.

A GPA was performed to evidence the correspondence between chemical parameters (Table 2S) and biological data (Table 4S) along the three studied mangrove plants. Fig. 8 shows the graphical representation of GPA, with the first function (CP1) explaining $53.5 \%$ of the total variance, and $27.0 \%$ for the second function (CP2). Also from Fig. 8 it is evident that four studied groups (corresponding to different levels of added-iron) can be clearly separated by considering the three studied mangrove species, mainly when exposed to the highest iron level $\left(100 \mathrm{mg} \mathrm{L}^{-1}\right)$. 


\section{a}

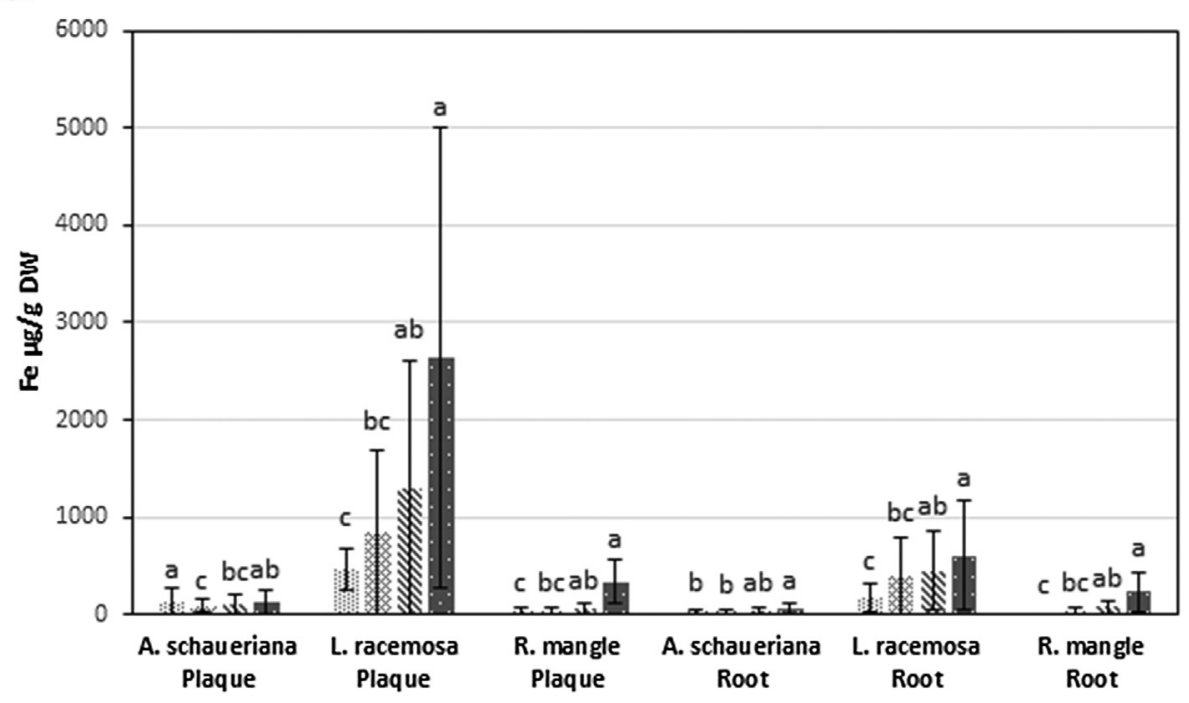

$0 \mathrm{mg} / \mathrm{L} \quad 10 \mathrm{mg} / \mathrm{L} \quad \leqslant 20 \mathrm{mg} / \mathrm{L} \quad 100 \mathrm{mg} / \mathrm{L}$

b

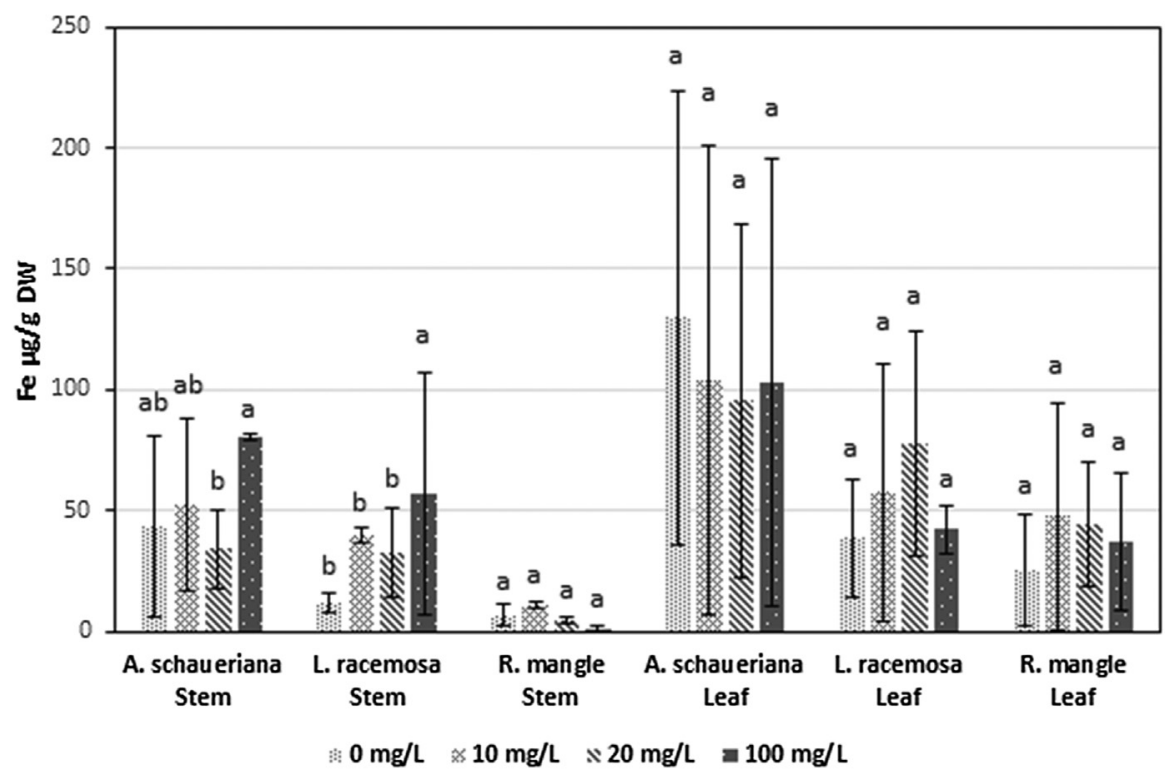

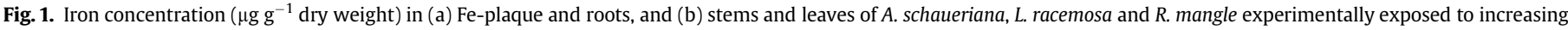

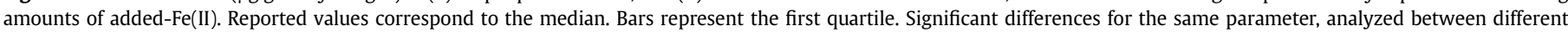
exposure concentrations for each plant, are pointed out using different letters (Kruskal-Wallis test, $P<0.05$ ).

\section{Discussion}

\subsection{Bioaccumulation of iron from exposure medium to different plant compartments}

Sections 3.1 and 3.2 describe results found for the uptake, translocation and bioaccumulation of iron from the exposure medium to different plant compartments, including secretion through salt glands present in leaves of two species. From Fig. 1A and Table $2 S$, it is evident that $L$. racemosa showed a dose-dependent behavior, with low levels of iron in both plaque and roots in controls, and a progressive increase until reaching maximum values at the highest added-iron concentration. It is important to note that the highest Fe retention in the Fe-plaque of $L$. racemosa was not due to increased root growth, since this species showed lower root biomass (average values of root dry weight: $L$. racemosa $=1.22 \mathrm{~g}$, A. schaueriana $=2.24 \mathrm{~g}, R$. mangle $=4.75 \mathrm{~g}$; Table $4 \mathrm{~S}$ for growth compared to controls). In addition, there was no correlation between Fe-plaque and root biomass for any of the three species. Also from Fig. $1 \mathrm{~A}$, we can observe that $R$. mangle presented a similar behavior to $L$. racemosa with a less pronounced response to increased amounts of added-iron. So far, roots of $L$. racemosa could be proposed as good bioindicator for iron in the mangrove environment.

Reports from the literature point out that compounds rich in iron oxides and hydroxides are attached to the root in wetland plants (Tripathi et al., 2014). Thus, the Fe-plaque could act as a buffer (Jiang et al., 2009; Xu et al., 2009), or as a barrier regulating 


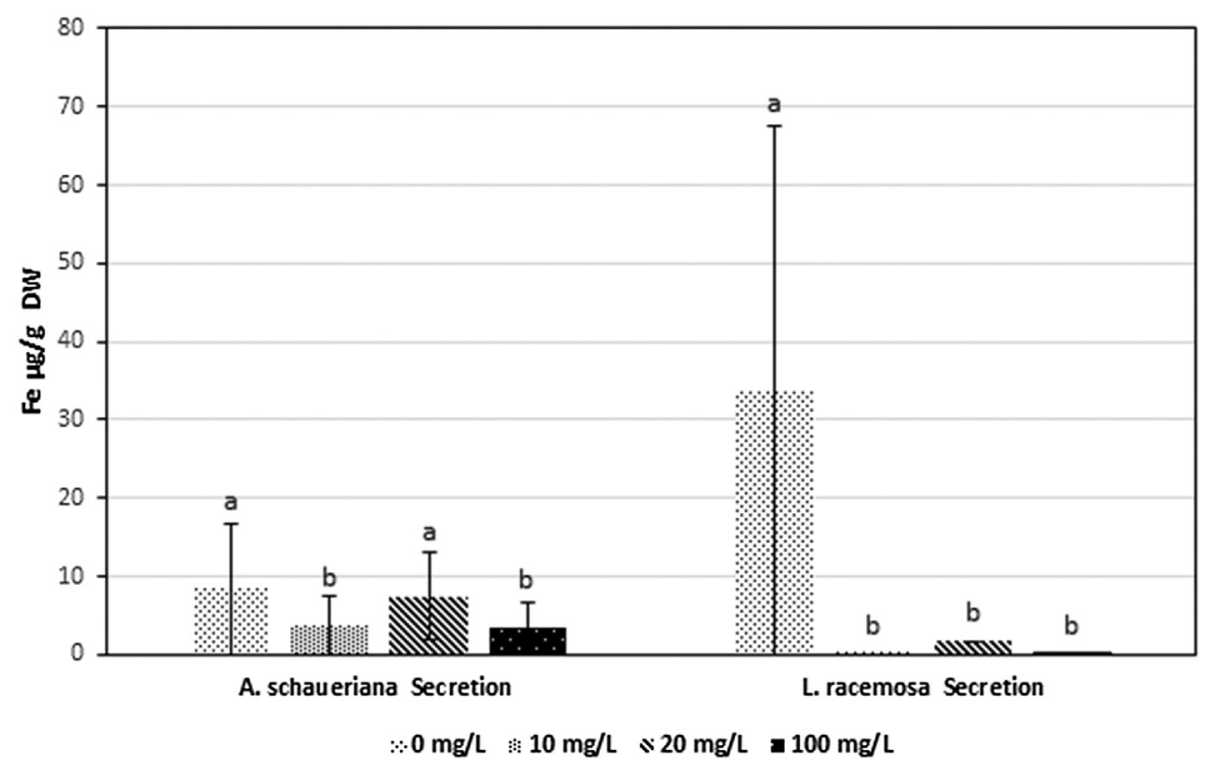

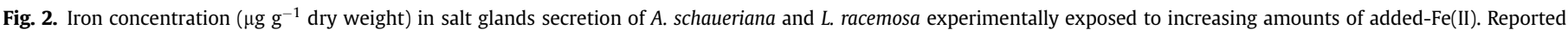

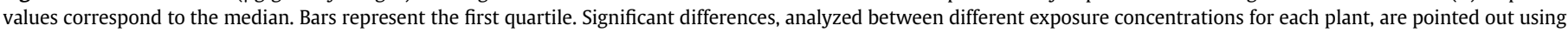
different letters (Kruskal-Wallis test, $P<0.05$ ).

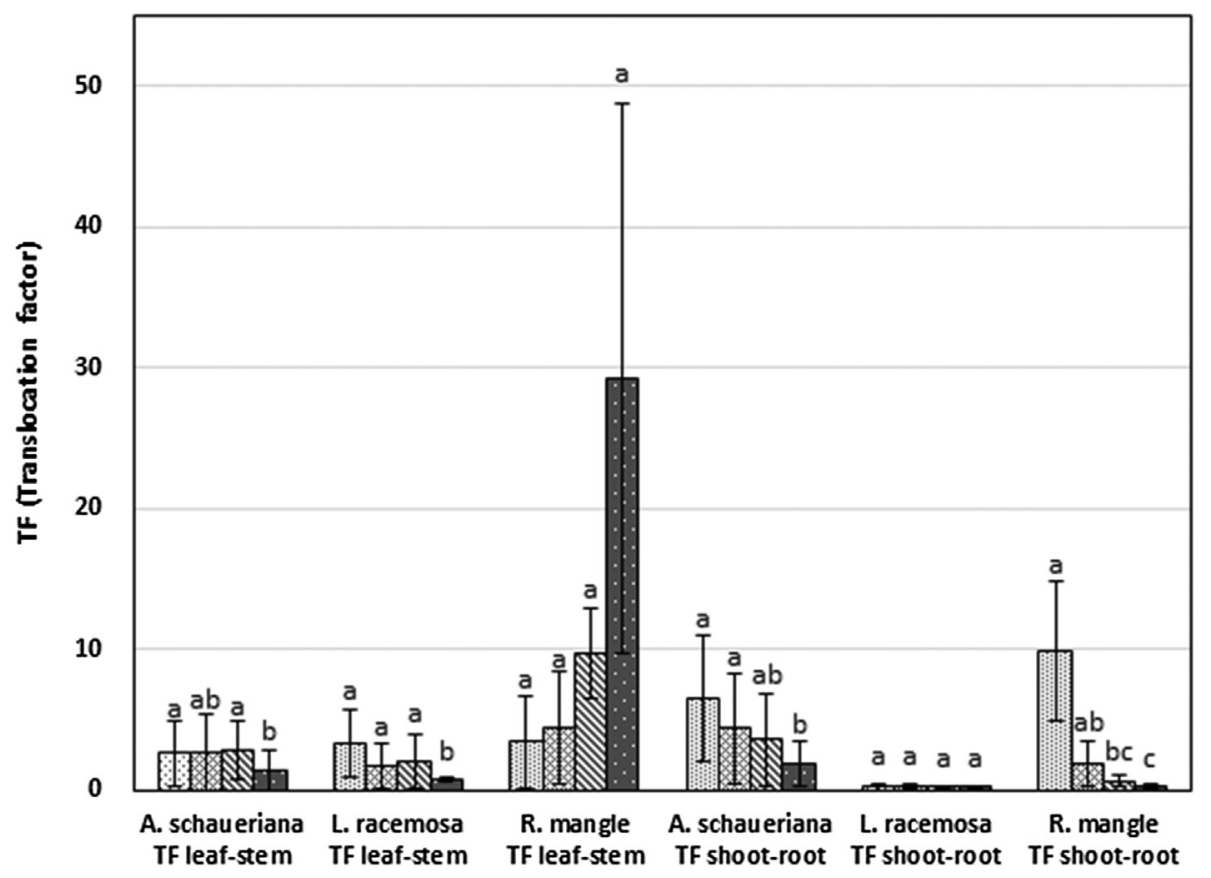

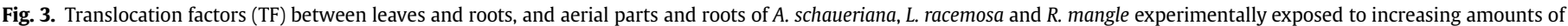

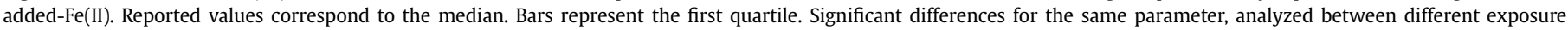
concentrations for each plant, are pointed out using different letters (Kruskal-Wallis test, $P<0.05$ ).

the uptake of metals by the plant (Cheng et al., 2014; Pan et al., 2014). Our current results with $L$. racemosa and $R$. mangle (Table 2S and Spearman statistical analysis) show a positive correlation between the amount of iron in the plaque and the corresponding level in the root (internal). Thus, it is possible to believe that the plaque is not limiting the input of iron from the environment to the root, but probably acting as a buffer.

From Fig. 1B, we observed that stems and leaves did not show a clear dose-dependent response, with the exception of stems from $A$. schaueriana and $L$. racemosa, which evidenced a significant increase of iron in stems of plants exposed to the highest concentration compared to controls.

We did not observe higher iron content in roots when compared to aerial parts of $A$. schaueriana. That result do not agree with reports from the literature on wild species exposed to environmental iron (e.g. Souza et al., 2015). The large bioaccumulation of iron found during this work in leaves of studied species reinforce the importance of this element for the structure of chlorophyll and photosynthesis (Briat et al., 2015). Furthermore, reports on the high accumulation of iron and other metals in whole-root 


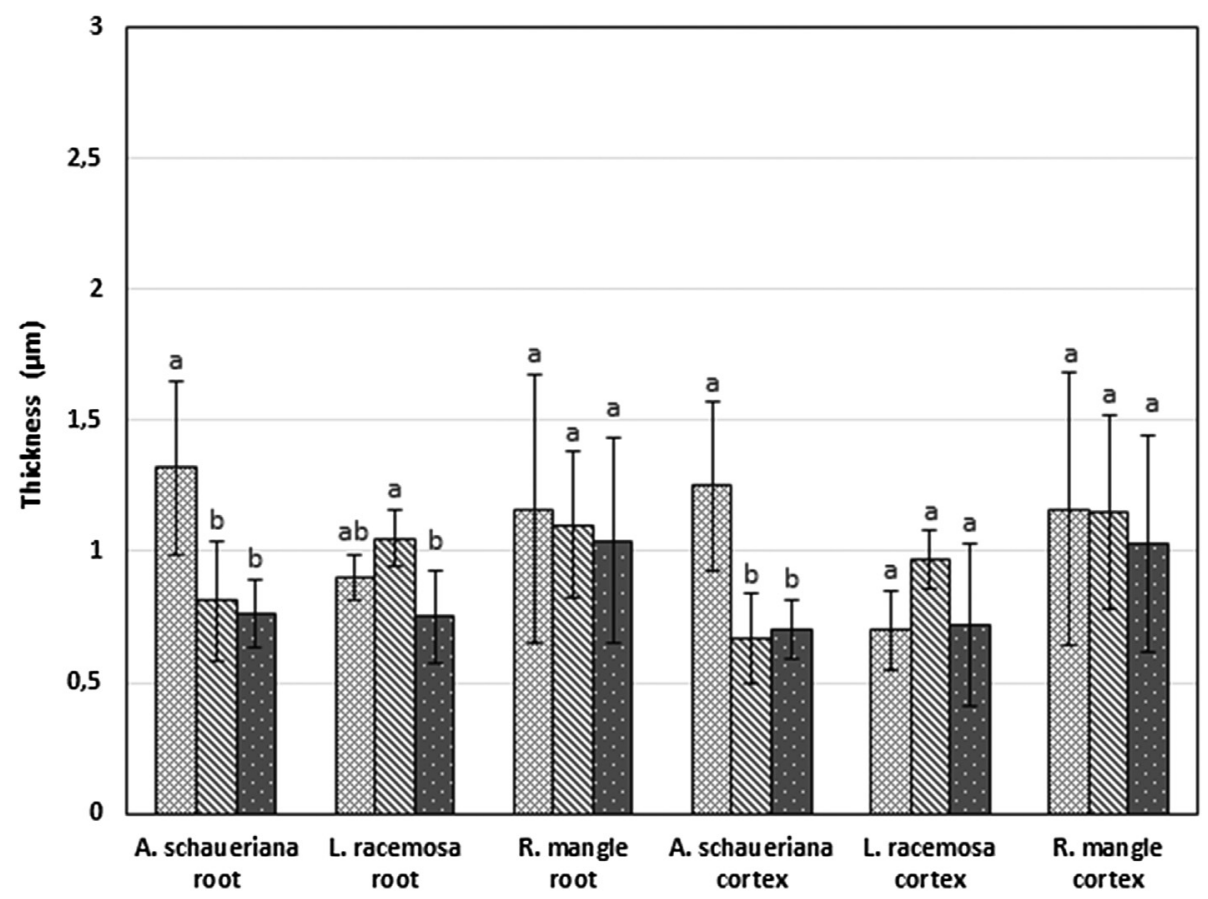

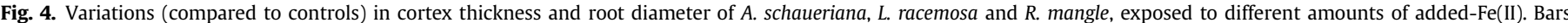

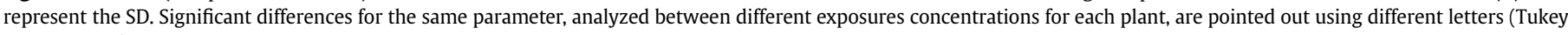
test, $P<0.05$ )

(plaque + internal) could be due to the retention of metals in the Fe-plaque, and not to a real bioaccumulation of these elements within the root (internal).

Differences found in the bioaccumulation of iron in roots, stems and leaves of the three studied species could be attributed to the regulatory mechanisms of salt in roots, which allows the entry of other metals in the process (Lacerda et al., 1985). Generally, salt secreting plants have higher concentrations of salt in the xylematic sap than those without salt-secreting glands (Scholander et al., 1962). In these cases, the salt ultra-filtration mechanism present in roots is responsible for this difference. In $R$. mangle, a species without salt glands, both external hypodermis and endodermis seem to work as two sheaths of the ultrafilter, which would explain the lower concentration of salt found in the sap (Werner and Stelzer, 1990). In this context, some studies have shown that metals concentrations, such as iron and other nutrients, are higher in leaves of salt-secreting plants when compared to species that do not secrete salt (Bernini et al., 2006; Cuzzuol and Campos, 2001; Sarangi et al., 2002). Higher concentrations of iron in leaves have been reported in Avicennia and Laguncularia, compared to the levels observed in Rhizophora (Bernini et al., 2006; Cuzzuol and Campos, 2001). Previous and current results from our research group demonstrate a preferential bioaccumulation of iron (and other elements) in leaves of $A$. schaueriana and $L$. racemosa in relation to R. mangle, corroborating this trend (Souza et al., 2014a, 2014b, 2015).

Fig. 2 shows that the secretion of iron from salt glands of $L$. racemosa is strongly inhibited upon exposure to added-iron, while A. schaueriana did not exhibit a clear change, despite showing significant drops in relation to controls at both 10 and $100 \mathrm{mg} \mathrm{L}^{-1}$ added-iron. So far, and considering this differential behavior between the studied plants when exposed to increasing $\mathrm{Fe}(\mathrm{II})$ concentrations, we could propose $L$. racemosa as the best bioindicator species for biomonitoring of iron in mangrove areas under risk of iron pollution. Furthermore, it would be worth a seasonal study and with other Fe dosages in order to evaluate whether the Fe secretion of this species maintain this response. Thus, the use of salt glands secretion from $L$. racemosa could be proposed as a method for sensing iron pollution without excessively disturbing the plant.

We observe similarities when comparing our current results with previous reports on the presence and distribution of metals in wild mangrove plants, using the same species sampled from the study area where propagules for this study were obtained (Vitória, Espírito Santo, Brazil). For instance, wild A. schaueriana showed a variable response between levels of iron in roots in relation to bioavailable iron in the environment (Souza et al., 2015); a similar behavior was reported for wild $R$. mangle (Souza et al., 2014b) and for wild $L$. racemosa (Souza et al., 2014a). These reports indicate that the sum of internal and external levels of iron in roots of wild $L$. racemosa ranged from 3995 to $7169 \mu \mathrm{g} \quad \mathrm{g}^{-1}$ (average $=4864 \mu \mathrm{g} \mathrm{g}^{-1}$; Souza et al., 2014a); in $R$. mangle, levels ranged from 804 to $13,477 \mu \mathrm{g} \mathrm{g}^{-1}$ (average $=4993 \mu \mathrm{g} \mathrm{g}^{-1}$; Souza et al., 2014b); and in A. schaueriana, levels ranged from 1319 to $8938 \mu \mathrm{g} \mathrm{g}^{-1}$ (average $=3205 \mu \mathrm{g} \mathrm{g}^{-1}$; Souza et al., 2015). So far, $L$. racemosa and $R$. mangle showed the highest average bioaccumulations of iron in roots, in agreement with our current results, although previous reports did not differentiate between Feplaque and root (external and internal iron in the root).

Furthermore, when comparing our current results for iron in leaves with field reports, we can observe that wild $L$. racemosa ranged from 107 to $427 \mu \mathrm{g} \mathrm{g}^{-1}$ (average $=211 \mu \mathrm{g} \mathrm{g}^{-1}$; Souza et al., 2014a); $R$. mangle ranged from 71 to $183 \mu \mathrm{g} \mathrm{g}^{-1}$

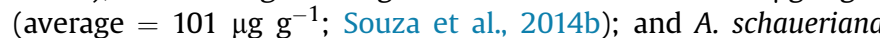
ranged from 97 to $665 \mu \mathrm{g} \mathrm{g}^{-1}$ (average $=308 \mu \mathrm{g} \mathrm{g}^{-1}$; Souza et al., 2015). Thus, results for iron in leaves from the three studied species also show good agreement between field and experimental exposure.

There are not previous reports on levels of iron in stems or in secretions from salt glands of studied plants evaluated in the field. 


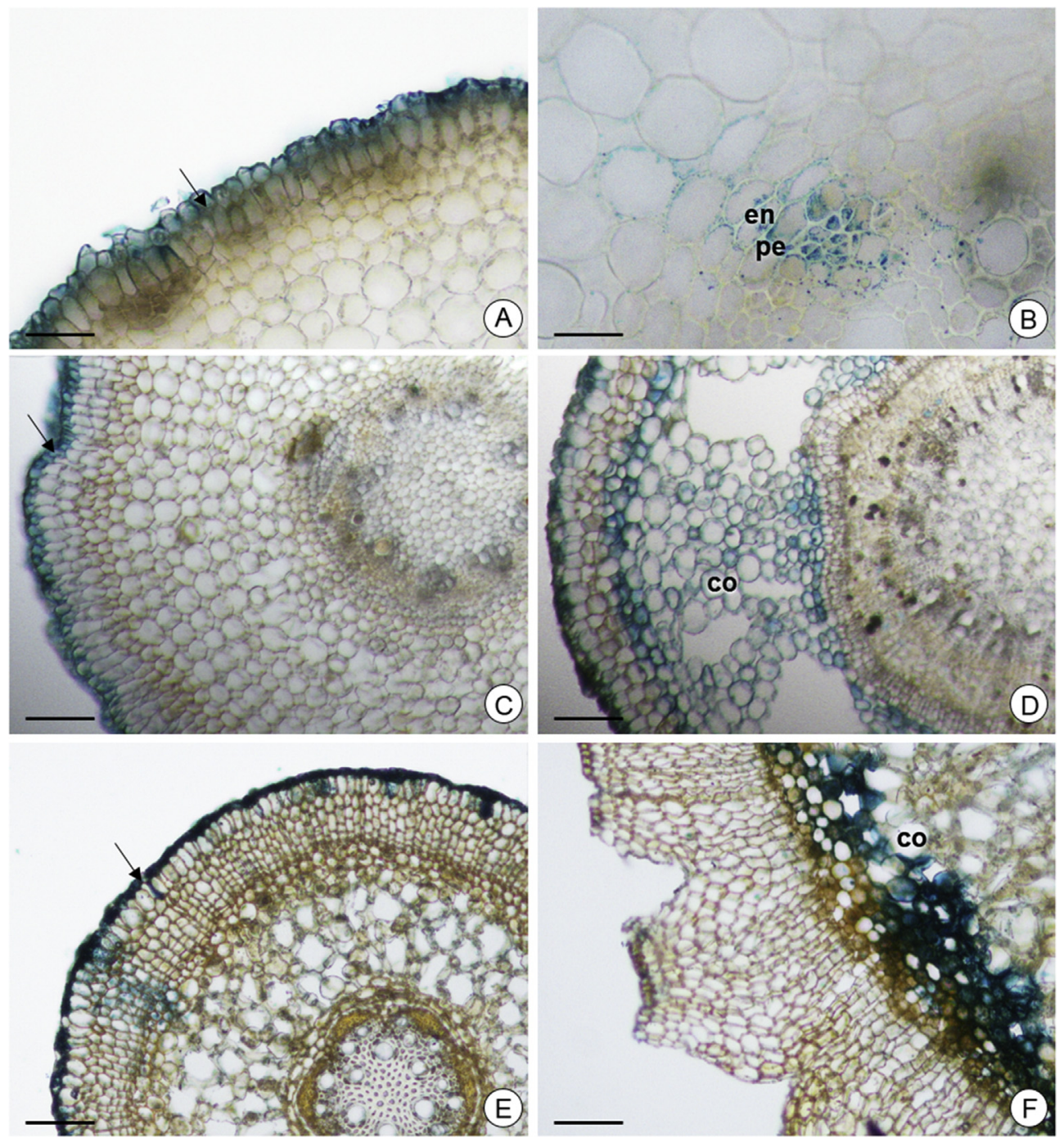

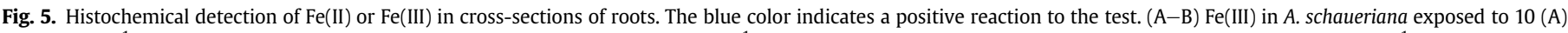

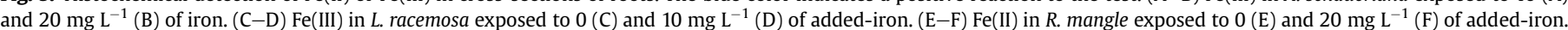

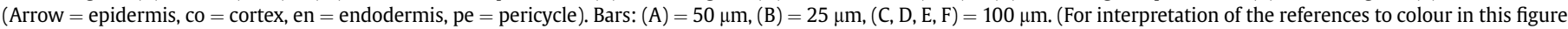
legend, the reader is referred to the web version of this article.)

To our knowledge, this is the first report evaluating secreted iron using increasing levels of $\mathrm{Fe}(\mathrm{II})$ during the growth of mangrove plants. It is worth to remark that controlled studies could help evaluate the behavior of a particular element, isolating it from the complex matrix associated with environmental samples.

\subsection{Translocation of iron from root to aerial plant compartments}

Differences observed with translocation factors (TF) were not so evident as in the results obtained with bioaccumulation. However, in general, increasing dosages of iron decreases the translocation of this metal into the plants (Table 2S, Fig. 3). A significant drop of translocation was found in $R$. mangle and A. schaueriana when evaluating aerial parts and roots (TFsr, TFlr and TFsh) (Fig. 3, Table 2S). This drop was dose-dependent. L. racemosa did not show changes in TFsr and TFsh throughout the studied concentrations of added-iron. This could evidence that higher concentrations of iron in the substrate could more negatively affect TF in $R$. mangle and A. schaueriana than in $L$. racemosa.

The statistical analysis showed a negative correlation
(Spearman) between TF and the concentration of iron in the plaque for $L$. racemosa and $R$. mangle. Some studies have demonstrated that the Fe-plaque can diminish the translocation of some metals from the root to aerial parts of the plant (Cheng et al., 2014; Liu et al., 2016). Thus, our current results agree with these reports.

\subsection{Anatomical and histochemical changes in exposed plants}

Few anatomic alterations were found in roots of plants exposed to increasing levels of iron (Table 4S). No correlation was observed between the Fe-plaque and the size of air gap. So far, an incidence of the aerenchymal area on the Fe-plaque in the root could be not expected. This last result does not agree with the report of Pi et al. (2010), on the effects of wastewater in two mangrove plants. They observed a greater area of air gap, with formation of more Feplaque, due to more radial oxygen loss (ROL). Deng et al. (2010) also noted the positive correlation between the aerenchymal area and formation of Fe-plaque, although they found that it was not due to the increased release of ROL, but to the root surface area for Fe-plaque grip. 

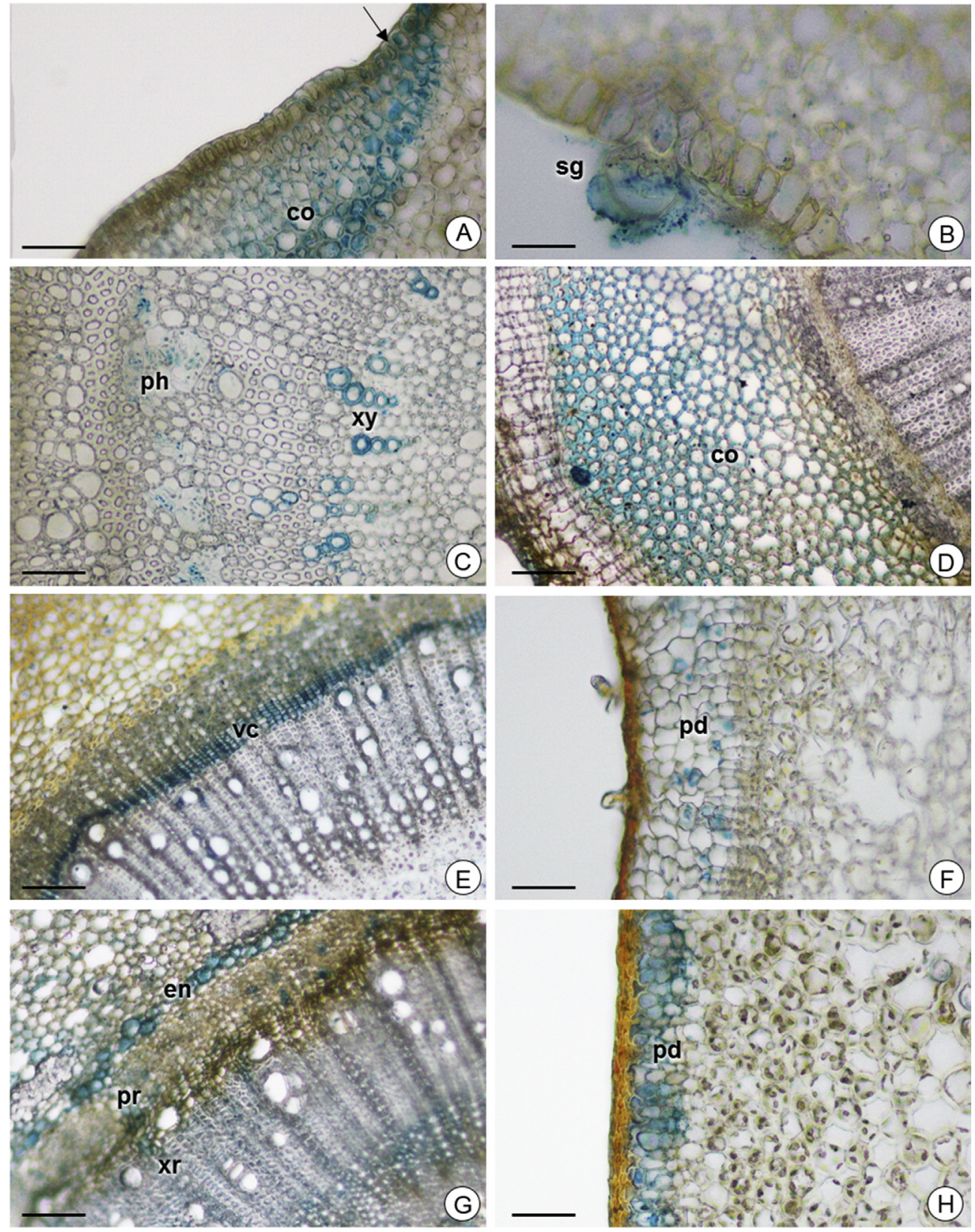

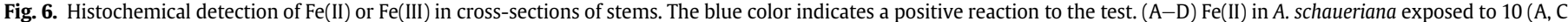

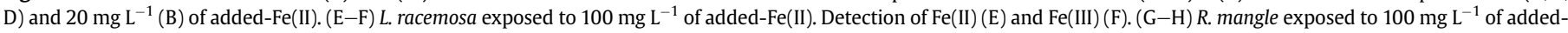

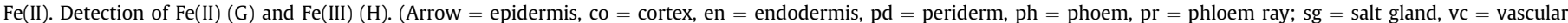

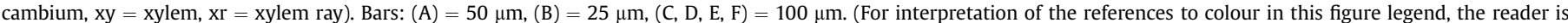
referred to the web version of this article.)

Although there was a decrease in root thickness of A. schaueriana and $L$. racemosa exposed at $100 \mathrm{mg} \mathrm{L}^{-1} \mathrm{Fe}$, there was not a decrease in root biomass between treatments (Fig. 4 and Table 4S). Some studies have shown varying responses in biomass of mangrove plants exposed to iron. Alongi (2010) found an increase in total plant biomass, but a reduction in root growth in only two out of five mangrove species exposed to iron. On the other hand, Cheng et al. (2012) observed a decrease in total biomass in six out of eight mangrove plants.

Plant epidermis was confirmed as the main compartment for iron bioaccumulation in roots (Fig. 5), probably being the main barrier to the uptake of metals by the plant. However, histochemical analysis did not detect bioaccumulation of iron in the root endoderm.

In stem sections, called our attention the accumulation of iron in the endoderm of R. mangle (Fig. 6G). In roots, endoderm is a place of recognized accumulation of metals (e.g. Di Toppi et al., 2012). This is mainly due to Casparian strips that provide an apoplastic barrier to most of the elements absorbed by the plant. Thus, this cell layer is responsible for to control input of water and ions dissolved for into the vascular cylinder (Schreiber et al., 1999). However, in stems, endoderm has not been linked to the accumulation of metals, but starch; within the endoderm are sedimentable amyloplasts, which are essentials for shoot gravitropism (Hashiguchi et al., 2013; Tasaka et al., 1999). In this study, we observed that the shoot endoderm can also be local of iron compartmentalization. 

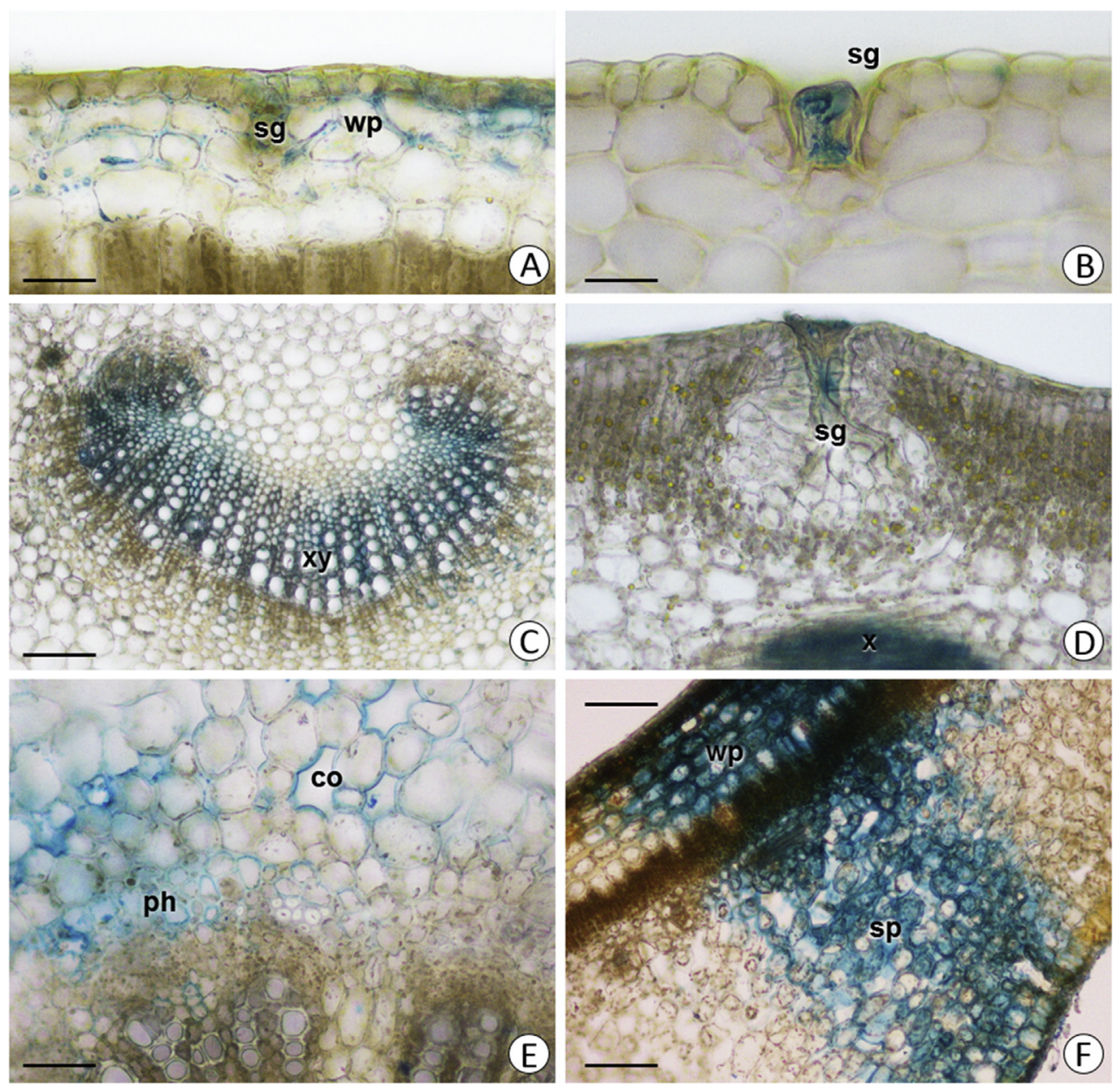

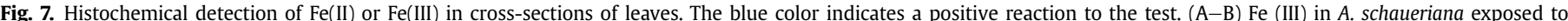

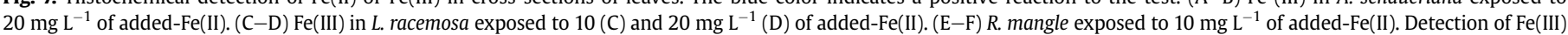

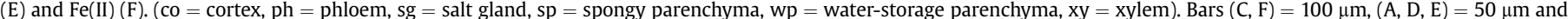
(B) $=25 \mu \mathrm{m}$. (For interpretation of the references to colour in this figure legend, the reader is referred to the web version of this article.)

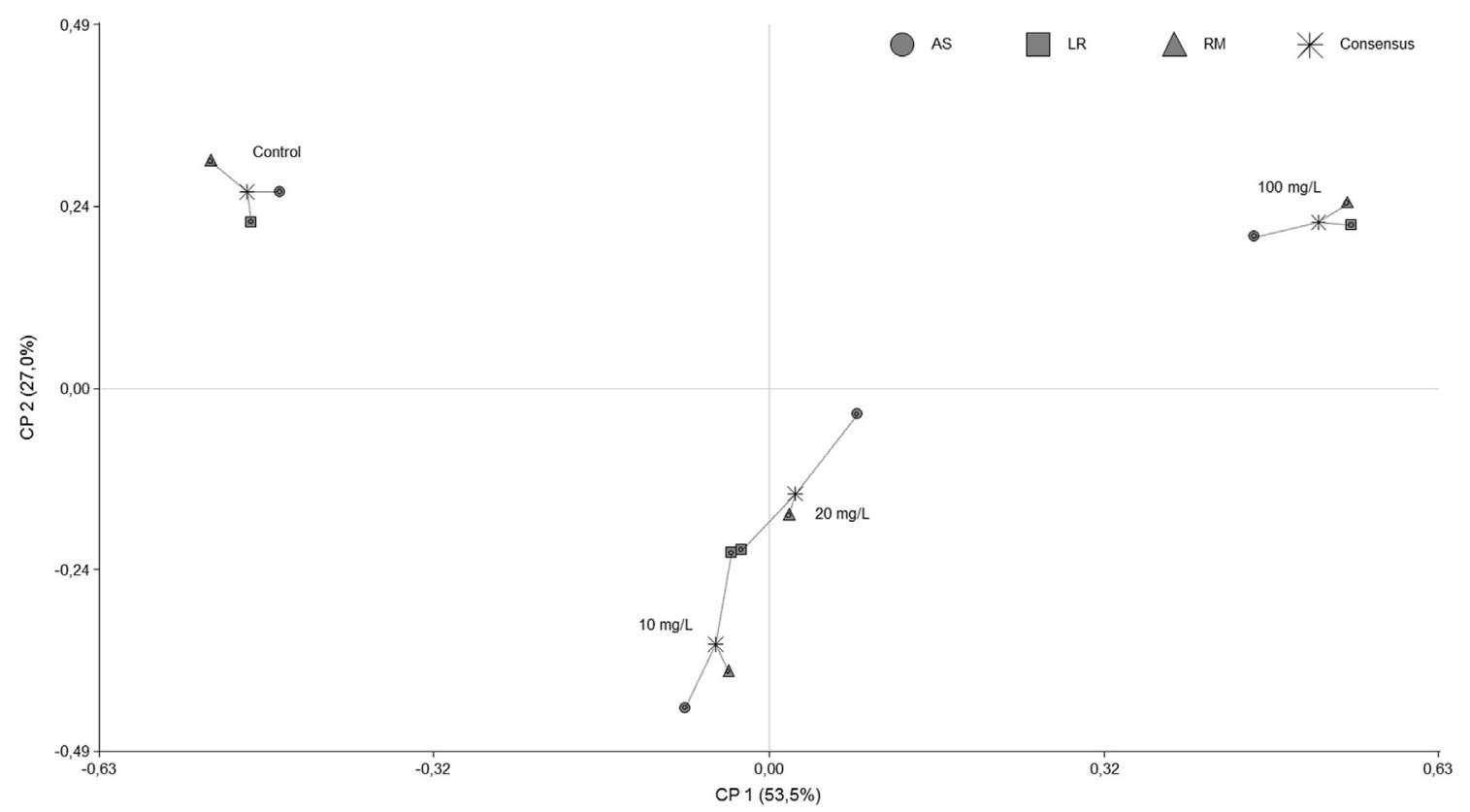

Fig. 8. Generalized Procrustes Analysis (GPA) of parameters studied for each treatment with added-Fe(II). (AS $=$ A. schaueriana, $\mathrm{LR}=L$. racemosa, RM $=R$. mangle). 
Similarly, it is important to highlight another site for iron accumulation, the vascular cambium of $L$. racemosa (Fig. $6 \mathrm{E}$ ). This lateral meristem with primordial function in secondary vascular tissue production (Nieminen et al., 2015), also showed $\mathrm{Zn}$ accumulation in plasmatic membrane-cell wall complex and cell corners of Solanum nigrum L. (Samardjieva et al., 2015). Nevertheless, to the best of our knowledge, we did not find in literature accumulation of iron or other metals in this meristem. Further studies are necessary to understand the relation between these micronutrients and their accumulation in vascular cambium.

In this study, the detection of iron by histochemical test in walls and cell content of leaves, roots and stems, suggests that there is a short-distance for the transport of iron via both apoplast and symplast, as reported by Bauer and Hell (2006). The release of iron in xylem vessels requires the efflux of Fe from the symplast to the apoplastic space and it is generally accepted that iron is present forming $\mathrm{Fe}(\mathrm{III})$-citrate complexes (Kim and Guerinot, 2007).

The secretion of iron through salt glands in A. schaueriana and L. racemosa was first tested using histochemistry (Fig. 7), and further confirmed by chemical analysis (ICP-MS) (Table 2S, Fig. 2). Our current results do not show an increase in secreted iron as added-iron concentrations rose. Conversely, L. racemosa showed a significant drop, while $A$. schaueriana presented a non-clear pattern with a significant drop when comparing controls with the higher iron-dose. These results do not agree with previous reports by Macfarlane and Burchett (1999, 2000) and Naiddo et al., (2014), who used increasing amounts of $\mathrm{Zn}$ and $\mathrm{Cu}$ in sediments, resulting in higher elimination these metal through salt glands. This contradictory result could indicate that the secretion of iron through salt glands could be interfered by other factors. Particularly, $L$. racemosa seems to be more sensitive to changes in the iron concentration. This could not be attributed to the drop in TF at higher added-iron concentrations, mainly because levels of iron in leaves of $L$. racemosa remained almost unchanged (Fig. 1B, Table 2S). Moreover, no correlation was found between the amount of secreted iron and the density of salt glands in leaves of L. racemosa or in A. schaueriana (Table 2S). Further research is needed to elucidate the inhibition observed in secreted iron. To our knowledge, this is the first report on salt glands in stems of $A$. schaueriana (Fig. 6).

\section{Conclusions}

Three studied plants are capable of biosensing the amount of added-Fe(II). L. racemosa showed a dose-dependent response in root and plaque, in addition to an inhibitory behavior with secretion of iron through salt glands. So far, we propose L. racemosa as the most appropriate species for biosensing the amount of iron in mangroves exposed to high amounts of this element due to environmental pollution. Moreover, further studies on inhibition of iron secretion through salt glands may allow the use of this parameter for environmental biomonitoring, avoiding excessive damage on wild plants, although bioaccumulation in the root of this species (both internal and plaque) presented the best response.

A drop in translocation factors between aerial parts of the plant and the root were evident and significant, mainly in $R$. mangle and A. schaueriana, indicating the impact on the plant transportation mechanism induced by high concentrations of added-Fe(II).

Changes in plants anatomy and histochemistry were not so evident as those observed with bioaccumulation and translocation.

To our knowledge, this is the first detailed report on the response of these plants to increasing iron concentrations under controlled conditions, complementing existing data on the behavior of the same plants under field exposure.

\section{Acknowledgements}

Thanks are owed to the Fundação de Amparo à Pesquisa do Estado de São Paulo (FAPESP), Brazil, for financial support (Proc. 2014/06870-0), and to the Coordenação de Aperfeiçoamento de Pessoal de Nivel Superior (CAPES) for the PhD scholarship held by the first author. S.R. Machado receives grants from the Conselho Nacional de Desenvolvimento Científico e Tecnológico, (CNPq, PQ 1, Proc. 302657/20111).

\section{Appendix A. Supplementary data}

Supplementary data related to this article can be found at http:// dx.doi.org/10.1016/j.envpol.2016.05.019.

\section{References}

Alongi, D.M., 2010. Dissolved iron supply limits early growth of estuarine mangroves. Ecology 91, 3229-3241.

Arrivabene, H.P., Souza, I.C., Có, W.L.O., Conti, M.M., Wunderlin, D.A., Milanez, C.R.D. 2015. Effect of pollution by particulate iron on the morphoanatomy, histochemistry, and bioaccumulation of three mangrove plant species in Brazil. Chemosphere 127, 27-34.

Bancroft, J.D., Stevens, A., Turner, D.R., 2008. Theory and Practice of Histological Techniques. Churchill Livingstone, New York.

Barbier, E.B., Hacker, S.D., Kennedy, C., Koch, E.W., Stier, A.C., Silliman, B.R., 2011. The value of estuarine and coastal ecosystem services. Ecol. Monogr. 81, 169-193.

Bauer, P., Hell, R., 2006. Translocation of iron in plant tissues. In: Barton, L.L Abadia, J. (Eds.), Iron Nutrition in Plants and Rhizospheric Microorganisms. Springer, Dordrecht, pp. 279-288.

Bernini, E., Silva, M.A.B., Carmo, T.M.S., Cuzzuol, G.R.F., 2006. Composição química do sedimento e de folhas das espécies do manguezal do estuário do Rio São Mateus, Espírito Santo, Brasil. Rev. Bras. Bot. 29, 689-699.

Brander, L.M., Wagtendonk, A.J., Hussain, S.S., McVittie, A., Verburg, P.H., de Groot, R.S., Van der Ploeg, S., 2012. Ecosystem service values for mangroves in Southeast Asia: a meta-analysis and value transfer application. Ecosyst. Serv. 1, 62-69.

Briat, J.F., Dubos, C., Gaymard, F., 2015. Iron nutrition, biomass production, and plant product quality. Trends Plant Sci. 20, 33-40.

Cardwell, R.D., Deforest, D.K., Brix, K.V., Adams, W.J., 2013. Do Cd, Cu, Ni, Pb, and Zn biomagnify in aquatic ecosystems? Rev. Environ. Contam. T. 226, 101-122.

Chappaz, A., Lyons, T.W., Gordon, G.W., Anbar, A.D., 2012. Isotopic fingerprints of anthropogenic molybdenum in lake sediments. Environ. Sci. Technol. 46, 10934-10940.

Cheng, H., Chen, D.T., Tam, N.F.Y., Chen, G.Z., Li, S.Y., Ye, Z.H., 2012. Interactions among $\mathrm{Fe}^{2+}, \mathrm{S}^{2-}$, and $\mathrm{Zn}^{2+}$ tolerance, root anatomy, and radial oxygen loss in mangrove plants. J. Exp. Bot. 63, 2619-2630.

Cheng, H., Wang, M., Wong, M.H., Ye, Z., 2014. Does radial oxygen loss and iron plaque formation on roots alter $\mathrm{Cd}$ and $\mathrm{Pb}$ uptake and distribution in rice plant tissues? Plant Soil 375, 137-148.

Clough, B., 2013. Continuing the Journey Amongst Mangroves. In: ISME Mangrove Educational Book Series No. 1. International Society for Mangrove Ecosystems (ISME), Okinawa, Japan and International Tropical Timber Organization (ITTO). Yokohama, Japan.

Costanza, R., D’Arge, R., Groot, R.D., Farber, S., Grasso, M., Hannon, B., Limburg, K. Naeem, S., O'Neill, R.V., Paruelo, J., Raskin, R.G., Sutton, P., Belt, M.V.D., 1997. The value of the world's ecosystem services and natural capital. Nature 387, 253-260.

Cuzzuol, G.R.F., Campos, A., 2001. Aspectos nutricionais na vegetação de manguezal do estuário do Rio Mucuri, Bahia, Brasil. Rev. Bras. Bot. 24, 227-234.

Defew, L.H., Mair, J.M., Guzman, H.M., 2005. An assessment of metal contamination in mangrove sediments and leaves from Punta Mala Bay, Pacific Panama. Mar. Pollut. Bull. 50, 547-552.

Deng, D., Wu, S.C., Wu, F.Y., Deng, H., Wong, M.H., 2010. Effects of root anatomy and Fe plaque on arsenic uptake by rice seedlings grown in solution culture. Environ. Pollut. 158, 2589-2595.

Di Rienzo, J.A., Casanoves, F., Balzarini, M.G., Gonzalez, L., Tablada, M., Robledo, C.W. 2010. InfoStat Versión. Grupo InfoStat, FCA, Universidad Nacional de Córdoba, Argentina.

Di Toppi, L.S., Vurro, E., De Benedictis, M., Falasca, G., Zanella, L., Musetti, R., Lenucci, M.S., Dalessandro, G., Altamura, M.M., 2012. A bifasic response to cadmium stress in carrot: early acclimatory mechanisms give way to root collapse further to prolonged metal exposure. Plant Physiol. Biochem. 58, 269-279.

Du, J., Yan, C., Li, Z., 2013. Formation of iron plaque on mangrove Kandalar. Obovata (SL) root surfaces and its role in cadmium uptake and translocation. Mar. Pollut. Bull. 74, 105-109.

Giri, C., Ochieng, E., Tieszen, L.L., Zhu, Z., Singh, A., Loveland, T., Masek, J., Duke, N., 2011. Status and distribution of mangrove forests of the world using earth observation satellite data. Glob. Ecol. Biogeogr. 20, 154-159. 
Hashiguchi, Y., Tasaka, M., Morita, M.T., 2013. Mechanism of higher plant gravity sensing. Am. J. Bot. 100, 91-100.

Hoagland, D.R., Arnon, D.I., 1950. The Water Culture Method for Growing Plants without Soils. California Agricultural Experimental Station, Berkeley.

IBEF, 2011. Instituto Brasileiro de Executivos de Finanças (IBEF) (accessed: 13.02.11.). http://ibefes.ning.com/page/ibefes-faz-visita-tecnica-a.

Jiang, F.Y., Chen, X., Luo, A.C., 2009. Iron plaque formation on wetland plants and its influence on phosphorus, calcium and metal uptake. Aquat. Ecol. 43, 879-890.

Kim, S.A., Guerinot, M.L., 2007. Mining iron: iron uptake and transport in plants. FEBS Lett. 581, 2273-2280.

Kobayashi, T., Nishizawa, N.K., 2012. Iron uptake, translocation, and regulation in higher plants. Annu. Rev. Plant Biol. 63, 131-152.

Lacerda, L.D., Rezende, C.E., José, D.V., Wasserman, J.C., Francisco, M.C., 1985. Mineral concentrations in leaves of mangrove trees. Biotropica 17, 21-27.

Lacerda, L.D., Souza, C.M.M., Pestana, M.H.D., 1989. Trace metals geochemical associations in sediments of a non-contaminated estuary. Ciência Cult. 41, 301-304.

Liu, C.Y., Gong, X.F., Chen, C.L., Yang, J.Y., Xu, S., 2016. The effect of iron plaque on lead translocation in soil- Carex cinerascens Kukenth. system. Int. J. Phytoremediat. 18, 1-9.

Liu, W.J., Zhu, Y.G., Smith, F.A., Smith, S.E., 2004. Do iron plaque and genotypes affect arsenate uptake and translocation by rice seedlings (Oryza sativa L.) grown in solution culture? J. Exp. Bot. 55, 1707-1713.

Lu, H., Liu, B., Zhang, Y., Ye, J., Yan, C., 2014. Comparing analysis of elements subcellular distribution in Kandelia obovata between SEM-EDX and chemical extraction. Aquat. Bot. 112, 10-15.

MacFarlane, G.R., Burchett, M.D., 1999. Zinc distribution and excretion in the leaves of the grey mangrove, Avicennia marina (Forsk.) Vierh. Environ. Exp. Bot. 41 $167-175$.

MacFarlane, G.R., Burchett, M.D., 2000. Cellular distribution of copper, lead and zinc in the grey mangrove, Avicennia marina (Forsk.) Vierh. Aquat. Bot. 68, 45-59.

Menezes, N.L.D., 2006. Rhizophores in Rhizophora mangle L: an alternative interpretation of so-called 'aerial roots'. An. Acad. Bras. Cienc 78, 213-226.

Morse, J.W., Rickard, D., 2004. Peer reviewed: chemical dynamics of sedimentary acid volatile sulfide. Environ. Sci. Technol. 38, 131A-136A.

Naidoo, G., Hiralal, T., Naidoo, Y., 2014. Ecophysiological responses of the mangrove Avicennia marina to trace metal contamination. Flora 209, 63-72.

Nath, B., Chaudhuri, P., Birch, G., 2014. Assessment of biotic response to heavy metal contamination in Avicennia marina mangrove ecosystems in Sydney Estuary, Australia. Ecotox. Environ. Safe 107, 284-290.

Nica, D.V., Bura, M., Gergen, I., Harmanescu, M., Bordean, D.M., 2012. Bioaccumulative and conchological assessment of heavy metal transfer in a soilplant-snail food chain. Chem. Cent. J. 6, 1-15.

Nieminen, K., Blomster, T., Helariutta, Y., Mähönen, A.P., 2015. Vascular cambium development. Arab. Book 13, 1-23.

O’Brien, T.P., Feder, N., McCully, M.E., 1964. Polychromatic staining of plant cell walls by toluidine blue O. Protoplasma 59, 368-373.

Otte, M.L., Dekkers, I.M.J., Rozema, J., Broekman, R.A., 1991. Uptake of arsenic by Aster tripolium in relation to rhizosphere oxidation. Can. J. Bot. 69, 2670-2677.

Pan, W., Wu, C., Xue, S., Hartley, W., 2014. Arsenic dynamics in the rhizosphere and its sequestration on rice roots as affected by root oxidation. J. Environ. Sci. 26 892-899.

Pi, N., Tam, N.F.Y., Wong, M.H., 2010. Effects of wastewater discharge on formation of Fe plaque on root surface and radial oxygen loss of mangrove roots. Environ. Pollut. 158, 381-387.

Pi, N., Tam, N.F.Y., Wong, M.H., 2011. Formation of iron plaque on mangrove roots receiving wastewater and its role in immobilization of wastewater-borne pollutants. Mar. Pollut. Bull. 63, 402-411.

Sadiq, M., Zaidi, T.H., 1994. Sediment composition and metal concentrations in mangrove leaves from the Saudi coast of the Arabian Gulf. Sci. Total Environ. $155,1-8$.

Samardjieva, K.A., Tavares, F., Pissarra, J., 2015. Histological and ultrastructural evidence for zinc sequestration in Solanum nigrum L. Protoplasma 252, 345-357.
Sarangi, R.K., Kathiresan, K., Subramanian, A.N., 2002. Metal concentrations in five mangrove species of the Bhitarkanika, Orissa, east coast of India. Indian J. Mar. Sci. 31, 251-253.

Scholander, P.F., Hammel, H.T., Hemmingson, E.A., Garey, W., 1962. Salt balance in mangroves. Plant Physiol. 37, 722-729.

Schreiber, L., Hartmann, K., Skrabs, M., Zeier, J., 1999. Apoplastic barriers in roots: chemical composition of endodermal and hypodermal cell walls. J. Exp. Bot. 50, 1267-1280.

Sherman, R.E., Fahey, T.J., Howarth, R.W., 1998. Soil-plant interactions in a neotropical mangrove forest: iron, phosphorus and sulfur dynamics. Oecologia 115, 553-563.

Silva, C.A.R., Lacerda, L.D., Rezende, C.E., 1990. Metals reservoir in a red mangrove forest. Biotropica 22, 339-345.

Souza, I., Bonomo, M.M., Morozesk, M., Rocha, L.D., Duarte, I.D., Furlan, L.M., Arrivabene, H.P., Monferrán, M.V., Matsumoto, S.T., Milanez, C.R.D., Wunderlin, D.A., Fernandes, M.N., 2014a. Adaptive plasticity of Laguncularia racemosa in response to different environmental conditions: integrating chemical and biological data by chemometrics. Ecotoxicology 23, 335-348.

Souza, I.C., Morozesk, M., Duarte, I.D., Bonomo, M.M., Rocha, L.D., Furlan, L.M., Arrivabene, H.P. Monferrán, M.V., Matsumoto, S.T. Milanez, C.R.D. Wunderlin, D.A., Fernandes, M.N., 2014b. Matching pollution with adaptive changes in mangrove plants by multivariate statistics. A case study, Rhizophora mangle from four neotropical mangroves in Brazil. Chemosphere 108, 115-124.

Souza, I.C., Rocha, L.D., Morozesk, M., Bonomo, M.M., Arrivabene, H.P., Duarte, I.D., Furlan, L.M., Monferrán, M.V., Matsumoto, S.T., Milanez, C.R.D., Wunderlin, D.A., Fernandes, M.N., 2015. Changes in bioaccumulation and translocation patterns between root and leaves of Avicennia schaueriana as adaptive response to different levels of metals in mangrove system. Mar. Pollut. Bull. 94, 176-184.

Tasaka, M., Kato, T., Fukaki, H., 1999. The endodermis and shoot gravitropism. Trends Plant Sci. 4, 103-107.

Taylor, G.J., Crowder, A.A., 1983. Use of the DCB technique for extraction of hydrous oxides from roots of wetlands plants. Am. J. Bot. 70, 1254-1257.

Tomlinson, P.B., 1994. The Botany of Mangroves. Cambridge University Press, New York.

Tripathi, R.D., Tripathi, P., Dwivedi, S., Kumar, A., Mishra, A., Chauhan, P.S., Norton, G.J., Nautiyal, C.S., 2014. Roles for root iron plaque in sequestration and uptake of heavy metals and metalloids in aquatic and wetland plants. Metallomics 6, 1789-1800.

Usepa, 2009. Risk-based Concentration Table. Philadelphia PA. United States Environmental Protection Agency, Washington.

Valiela, I., Bowen, J.L., York, J.K., 2001. Mangrove forests: one of the world's threatened major tropical environments. Bioscience 51, 807-815.

Veerasingam, S., Vethamony, P., Murali, R.M., Fernandes, B., 2015. Depositional record of trace metals and degree of contamination in core sediments from the Mandovi estuarine mangrove ecosystem, west coast of India. Mar. Pollut. Bull. $91,362-367$.

Vo, Q.T., Kuenzer, C., Vo, Q.M., Moder, F., Oppelt, N., 2012. Review of valuation methods for mangrove ecosystem services. Ecol. Indic. 23, 431-446.

Werner, A., Stelzer, R., 1990. Physiological responses of the mangrove Rhizophora mangle grown in the absence and presence of $\mathrm{NaCl}$. Plant Cell Environ. 13, $243-255$.

Wunderlin, D.A., Díaz, M.P., Amé, M.V., Pesce, S.F., Hued, A.C., Bistoni, M.A., 2001 Pattern recognition techniques for the evaluation of spatial and temporal variations in water quality. A case study: Suquía River Basin (Córdoba, Argentina). Water Res. 35, 2881-2894.

Xu, D., Xu, J., He, Y., Huang, P.M., 2009. Effect of iron plaque formation on phosphorus accumulation and availability in the rhizosphere of wetland plants. Water Air Soil Pollut. 200, 79-87.

Youssef, T., Saenger, P., 1996. Anatomical adaptive strategies to flooding and rhizosphere oxidation in mangrove seedlings. Aust. J. Bot. 44, 297-313.

Zhou, Y.W., Zhao, B., Peng, Y.S., Chen, G.Z., 2010. Influence of mangrove reforestation on heavy metal accumulation and speciation in intertidal sediments. Mar. Pollut. Bull. 60, 1319-1324. 